\title{
ASSESSMENT OF THE EFFECTS OF STEADY-STATE BUPROPION ON THE PHARMACOKINETIC PROFILE OF ZOLPIDEM IN HEALTHY VOLUNTEERS
}

\author{
ANA-MARIA GHELDIU ${ }^{1}$, LAURIAN VLASE ${ }^{2 *}$, ADINA POPA $^{3}$, DANA MUNTEAN ${ }^{2}$, CORINA $^{2}$ \\ BOCȘAN $^{4}$, ANCA BUZOIANU $^{4}$, MARIA NEAG $^{4}$, DANIEL LEUCUȚA ${ }^{5}$, CORINA BRICIU ${ }^{3}$
}

"Iuliu Hațieganu” University of Medicine and Pharmacy, Cluj-Napoca, Romania

${ }^{I}$ Faculty of Pharmacy, Department of Pharmaceutical Botany

${ }^{2}$ Faculty of Pharmacy, Department of Pharmaceutical Technology and Biopharmacy

${ }^{3}$ Faculty of Pharmacy, Department of Clinical Pharmacy

${ }^{4}$ Faculty of Medicine, Department of Pharmacology, Toxicology and Clinical Pharmacology

${ }^{5}$ Faculty of Medicine, Department of Medical Informatics and Biostatistics

*corresponding author: laurian.vlase@umfcluj.ro

\begin{abstract}
The study's purpose was to evaluate if bupropion, an antidepressant agent, can influence the pharmacokinetic profile of zolpidem, a sedative/hypnotic drug, and its main metabolite (zolpidem phenyl-4-carboxylic acid, Z4CA). The open-label, non-randomized, sequential clinical trial consisted of two periods: Period 1, when each volunteer received a single dose of zolpidem $5 \mathrm{mg}$ and Period 2, when a combination of zolpidem $5 \mathrm{mg}$ and bupropion $300 \mathrm{mg}$ was administered, after a 7-day pre-treatment with bupropion. Pharmacokinetic analysis used for the non-compartmental approach and safety evaluations were conducted during the study. Bupropion pre-treatment decreased mean $\mathrm{C}_{\max }$ and $\mathrm{AUC}_{0-\infty}$ for zolpidem and increased the same parameters for Z4CA. Most of zolpidem's pharmacokinetic parameters displayed statistically significant differences between study periods. These results demonstrated that a pharmacokinetic interaction does occur between these drugs, possibly due to CYP3A4 induction, hypothesis which needs to be further investigated.
\end{abstract}

\section{Rezumat}

Scopul studiului a fost de a evalua dacă bupropiona, un antidepresiv, poate influența profilul farmacocinetic al zolpidemului, un sedativ/hipnotic, și al principalului său metabolit (zolpidem acid fenil-4-carboxilic, Z4CA). Studiul clinic deschis, nonrandomizat, secvențial a constat în două perioade: Perioada 1, când fiecare voluntar a primit o doză unică de zolpidem $5 \mathrm{mg}$ și Perioada 2, când s-au co-administrat zolpidem $5 \mathrm{mg}$ și bupropionă $300 \mathrm{mg}$, după 7 zile de pre-tratament cu bupropionă. Analiza farmacocinetică a utilizat metoda non-compartimentală, iar în timpul studiului s-a urmărit și evaluarea siguranței terapiei. Pre-tratamentul cu bupropionă a scăzut valoarea medie a $C_{\max }$ şi $\mathrm{AUC}_{0-\infty}$ pentru zolpidem şi a crescut aceiaşi parametri pentru Z4CA. Majoritatea parametrilor farmacocinetici ai zolpidemului au prezentat diferențe semnificative statistic între perioadele de studiu. Aceste rezultate au demonstrat că există o interacțiune farmacocinetică între aceste medicamente, posibil datorită inducției CYP3A4, ipoteză care trebuie investigată în continuare.

Keywords: zolpidem, bupropion, pharmacokinetic interaction, healthy volunteers

\section{Introduction}

Zolpidem is a non-benzodiazepine agent of the imidazopyridine class that acts by binding selectively to the benzodiazepine $\omega 1$-receptor subtype. Due to its high affinity for the $\alpha 1$-gamma-aminobutyric acid type $\mathrm{A}\left(\mathrm{GABA}_{\mathrm{A}}\right)$ receptors, the drug possesses a strong hypnotic action and very weak anxiolytic, myorelaxant and anticonvulsant properties [8]. It is currently available as immediate-release (IR) and extended-release (ER) tablet formulations, oral spray formulation and sublingual tablets. Depending on the pharmaceutical formulation, zolpidem can be used to reduce sleep latency, to improve sleep maintenance in elderly and non-elderly patients and also to aid patients that present middle-of-the-night wakefulness and difficulty returning to sleep $[13,21]$. In comparison to benzodiazepines, it has a more favourable safety profile when considering the risk for next-day hangover effects or potential for rebound insomnia, and is not associated with significant dependence or abuse risks [21].

The oral administration of zolpidem is characterized by a rapid absorption and an absolute bioavailability of about $70 \%$. The drug is highly bound to plasma proteins (around 92\%) and it preferably should be taken on an empty stomach as it was revealed that food prolongs $t_{\max }$ by $60 \%[21,28]$. It is subjected to extensive hepatic metabolism, and although zolpidem is a substrate to several distinct CYP450 isoenzymes, 
FARMACIA, 2019, Vol. 67, 3

its major metabolic pathway is mediated by CYP3A4 (61\%); to a lesser extent, this drug is metabolized by other CYP isoforms such as: 2C9 (22\%), 1A2 (14\%), $2 \mathrm{C} 19$ and 2D6 (<3\%) [36]. Zolpidem is converted via oxidation and hydroxylation to three pharmacologically inactive metabolites, of which the 4-carboxy-derivative is the predominant one (zolpidem phenyl-4-carboxylic acid; Z4CA), representing $72 \%$ up to $86 \%$ of the administered dose [18, 28].

Bupropion is an antidepressant whose mechanism of action includes the inhibition of both norepinephrine and dopamine reuptake $[1,16]$. Apart from its use in the management of major depressive disorder, indication for which it was developed, bupropion is also registered as a smoking cessation agent and is used as an off-label treatment option for attention deficit hyperactivity disorder (ADHD), neuropathic pain and sexual dysfunction induced by selective serotonin reuptake inhibitors (SSRIs) [31, 32, 41]. In addition, bupropion/naltrexone fixed-dose drug combination is considered a new-generation antiobesity medication that has been marketed in the United States of America (USA) since approval in 2014 and in the European Union (EU) since 2015 [24]. This agent is rapidly absorbed from the gastrointestinal tract following oral administration, process that is unaffected by concomitant intake of food. Bupropion is $84 \%$ bound to human plasma proteins and is subjected to extensive metabolism in the liver, which leads to formation of three pharmacologically active metabolites (hydroxybupropion, erythrohydrobupopion and threohydrobupropion) [27]. The main active metabolite, hydroxybupropion, is approximately half as potent as the parent drug, while the other two possess only $20 \%$ of the activity of bupropion. CYP2B6 is considered the primary CYP450 isoenzyme involved in the biotransformation of this agent, while other isoforms such as CYP1A2, 2A6, 2C9, 2D6, 2E1 and $3 \mathrm{~A} 4$ play a relatively minor role [16]. Bupropion is described as a potent inhibitor of CYP2D6, a property responsible for interactions with drugs that are substrates of the same isoenzyme [11].

Published data revealed an increased trend in the frequency of prescribing sleep medications such as second generation benzodiazepines or Z-drugs (zopiclone, zolpidem, zaleplon) as insomnia is currently viewed as an important public health concern that has a negative impact not only on health, but also on work performance and quality of life [3]. This medical condition can be acknowledged as a prodromal symptom, one of the earlier symptoms of a depressive disorder or an independent risk factor for depression. Some studies also support the idea of a bidirectional relationship between insomnia and depression [29]. The prevalence of insomnia is higher for the depressed and cardiovascular patients, but it was also found to be one of the risk factors for the aforementioned conditions $[5,30,40]$.
The empirical treatment approaches that address insomnia comorbid with depression include prescription of a sedative antidepressant alone, co-prescription of two antidepressants, or of an antidepressant with a hypnotic drug [30]. When prescribing bupropion, a particularity of this medication has to be considered. A meta-analysis concluded that the highest incidence of insomnia for second-generation antidepressants was found for bupropion and desvenlafaxine [2]. Moreover, whenever antidepressants with an activating role, including bupropion, are recommended in depressed patients with insomnia, the use of a hypnotic agent alongside the antidepressant is recommended, especially in the first weeks of therapy and with the precise purpose of alleviating insomnia [39]. Another clinical context that can require the association of bupropion and a hypnotic agent refers to the smoking cessation process. Not only smoking represents a risk factor for insomnia, but sleep deficits may be exacerbated following cessation both as an abstinence symptom and as a side effect of smoking cessation agents. For this reason, the use of hypnotic agents as an adjunctive treatment during the period of discontinuing tobacco smoking can be taken into consideration [25].

All the information mentioned above emphasize the fact that co-administration of bupropion and zolpidem in clinical practice is possible and any information related to the safety and efficacy profile of this combination can be very useful. Therefore, this study aimed to provide more information on this aspect.

\section{Materials and Methods}

Subjects

Twenty healthy Caucasian and non-smoking volunteers were enrolled in the clinical study. The health status of each volunteer was assessed based on medical history, physical examination, haematological testing and electrocardiogram. They had no history of alcohol or drug abuse and did not take any regular medication. All volunteers gave their written informed consent prior to study inclusion.

The study was conducted according to the principles of Declaration of Helsinki (1964) and its amendments (Tokyo 1975, Venice 1983, Hong Kong 1989) and Good Clinical Practice (GCP) rules. The clinical protocol was reviewed and approved by the Ethics Committee of the "Iuliu Haţieganu" University of Medicine and Pharmacy, Cluj-Napoca, Romania.

Study design

The present study was an open-label, single-centre, non-randomized clinical trial, that consisted of 2 periods. During the first period (Reference, Study period 1), each volunteer received a single dose of $5 \mathrm{mg}$ zolpidem, whilst during the second period (Test, Study period 2), zolpidem $5 \mathrm{mg}$ was co-administered with bupropion $300 \mathrm{mg}$, after a previous treatment 
with bupropion. The 7-day bupropion pre-treatment regimen included the administration of this agent as a single daily dose of $150 \mathrm{mg}$ for 3 days, followed by its intake as a single daily dose of $300 \mathrm{mg}$ for 4 days. This dosage regimen was necessary in order to achieve steady-state plasma levels for bupropion, but it also represented a medication schedule frequently encountered in routine clinical practice. All drugs were administered in the morning, under fasted state and with at least $150 \mathrm{~mL}$ water. Drugs, smoking and alcohol were not allowed to be taken during the course of the study.

The pharmaceutical products used were Stilnox ${ }^{\circledR}$ (10 mg film-coated tablets, Sanofi-Aventis, Romania) for zolpidem and Elontril ${ }^{\circledR}$ for bupropion $(150 \mathrm{mg}$ and $300 \mathrm{mg}$ modified release tablets, Glaxo Smith Kline, Romania).

Sample collection and analytical method description On the first and last day of the study, venous blood $(5 \mathrm{~mL})$ was drawn into heparinized tubes, before zolpidem administration and after, at the following times: $0.5,1,1.5,2,2.5,3,4,6,8,10,12,24,36$ and 48 hours. The separated plasma was stored frozen $\left(-20^{\circ} \mathrm{C}\right)$ until analysis.

Zolpidem and Z4CA plasma concentrations were estimated by using a validated high-throughput liquid chromatography (HPLC) tandem mass spectrometry analytical method. The HPLC system was an Agilent 1100 series (binary pump, autosampler, thermostat) (Agilent Technologies, USA) and was coupled with a Brucker Ion Trap SL (Brucker Daltonics GmbH, Germany). The chromatographic column used was a Zorbax SB-C18 (100 mm x $3.0 \mathrm{~mm}$ i.d., $3.5 \mu \mathrm{m})$ (Agilent Technologies). The same bioanalytical method was used for quantification of zolpidem in another pharmacokinetic (PK) drug-drug interaction study [12]. Pharmacokinetic analysis

Standard non-compartmental analysis methods were employed to determine the main PK parameters of zolpidem and its metabolite (Z4CA). The maximum plasma concentration $\left(\mathrm{C}_{\max }, \mathrm{ng} / \mathrm{mL}\right)$ and the time to reach the peak plasma concentration $\left(t_{\max }, h\right)$ were obtained by direct inspection of the plasma concentration-time profile of each subject. The linear trapezoidal method was used with the purpose of estimating the area under the concentration-time curve from time 0 to time of last quantifiable concentration $\left(\mathrm{AUC}_{0-\mathrm{t}}, \mathrm{ng}^{*} \mathrm{~h} / \mathrm{mL}\right)$. The area under the concentration-time curve from time 0 to infinity $\left(\mathrm{AUC}_{0-\infty}, \mathrm{ng}^{*} \mathrm{~h} / \mathrm{mL}\right)$ was calculated by adding the $\mathrm{C}_{\mathrm{t}} / \mathrm{k}_{\mathrm{el}}$ to $\mathrm{AUC}_{0-\mathrm{t}}$, where $\mathrm{C}_{\mathrm{t}}$ is the last quantifiable drug concentration and $\mathrm{k}_{\mathrm{el}}$ is the elimination rate constant. The elimination rate constant $\left(\mathrm{k}_{\mathrm{el}}, \mathrm{h}^{-1}\right)$ was estimated by the least-square regression of plasma concentration-time data points of the terminal region from the semi-logarithmic dependence corresponding to first-order kinetics. The half-life time $\left(\mathrm{t}_{1 / 2}, \mathrm{~h}\right)$ was calculated as $0.693 / \mathrm{k}_{\mathrm{el}}$. The apparent clearance $\left(\mathrm{Cl}_{-} \mathrm{F}\right.$,
$\mathrm{L} / \mathrm{h}$ ) was obtained by dividing the administered dose by the $\mathrm{AUC}_{0-\infty}$ or by considering the $\mathrm{k}_{\mathrm{el}}$ and the apparent volume of distribution $(\mathrm{Vz} F, \mathrm{~F})$, and the obtained value is not the real clearance as it is affected by the bioavailability of the drug. Vz_F does not represent a physiological volume; it is a proportionality constant used in order to relate the plasma drug concentration at a certain time $\left(\mathrm{C}_{\mathrm{p}}\right)$ with the amount of drug (D) and is also affected by the bioavailability of the drug.

All pharmacokinetic investigations were performed by using Phoenix WinNonlin 6.1 (Certara, USA) software.

\section{Statistical analysis}

The sample size for the mean differences between pharmacokinetic AUC parameter was computed using G*Power (Version 3.0.10, Germany) [9]. Several simulations were made, using a 0.05 level of significance, a power of $80 \%$, for a two tailed p-value paired ttest, and a range of correlation coefficient values between the two periods from 0.01 to 0.99 . Two scenarios were checked: as inhibitor - using the mean and standard deviation from an article using $5 \mathrm{mg}$ (the same dose with the one in the current study) of zolpidem with ciprofloxacine and fluvoxamine, that had an inhibiting effect, and as inducer - using the mean and standard deviation from an article using $5 \mathrm{mg}$ zolpidem with carbamazepine, that had an inducer effect [12, 34, 35]. A sample size was estimated ranging from 3 to 16 for the inhibitor effect, and a sample size ranging from 8 to 16 for the inducer effect, thus finally was chosen a sample size of 20 subjects for the present study.

Analysis of variance (ANOVA) was employed to compare the calculated PK parameters of zolpidem and its metabolite for the two study periods, using general linear model procedures in which the acknowledged sources of variation were both the subject and the treatment. The test was performed using Phoenix WinNonlin 6.1 (Certara, USA) software and statistical significance was defined as $p<0.05$. Safety evaluation

A safety assessment was carried out throughout both study periods and included the monitoring and recording of all adverse events (AEs). All exhibited symptoms that were most probably induced by the administered drugs were recorded as AEs. Drowsiness intensity was evaluated as 1 (mild), 2 (moderate) and 3 (severe) by using an empirical scale. The onset and duration of this effect were also registered.

\section{Results and Discussion}

\section{Demographics}

The study population consisted of 20 healthy volunteers, respectively 8 women and 12 men. The demographic characteristics of the volunteers were as follows: the mean age was $25.05 \pm 4.01$ years, the mean weight 
was $68.77 \pm 12.58 \mathrm{~kg}$, and the mean height was $1.73 \pm 0.08 \mathrm{~m}$ (mean \pm standard deviation (SD)). All subjects completed the study without protocol deviations.

Pharmacokinetic and statistical analysis

The mean values of the main PK parameters of zolpidem, when administered alone or in combination with bupropion are presented in Table I (zolpidem). As for Z4CA, a summary of the pharmacokinetic parameters of zolpidem's main metabolite, before and after pre-treatment with bupropion, is illustrated in Table II.

Pharmacokinetic (PK) parameters of zolpidem in 20 healthy volunteers, after a single oral dose of $5 \mathrm{mg}$ zolpidem,

before and after pre-treatment with bupropion (BUP) and the results of the statistical test used for comparison

\begin{tabular}{lccc}
\hline \multicolumn{1}{c}{ PK parameters ${ }^{\text {a }}$} & Zolpidem & Zolpidem + BUP & $\boldsymbol{p}^{2}$ value $^{\mathbf{b}}, \mathbf{A N O V A}$ \\
\hline $\mathrm{C}_{\max }(\mathrm{ng} / \mathrm{mL})$ & $65.48 \pm 28.49$ & $52.3 \pm 24.27$ & $0.013664, \mathrm{~S}$ \\
\hline $\mathrm{t}_{\max }(\mathrm{h})$ & $1.28 \pm 0.9$ & $1.33 \pm 0.86$ & $0.698360, \mathrm{NS}$ \\
\hline $\mathrm{AUC}_{0-\mathrm{t}}(\mathrm{ng} * \mathrm{~h} / \mathrm{mL})$ & $327.06 \pm 241.11$ & $208.25 \pm 116.83$ & $0.005957, \mathrm{~S}$ \\
\hline $\mathrm{AUC}_{0-\infty}(\mathrm{ng} * \mathrm{~h} / \mathrm{mL})$ & $340.34 \pm 249.02$ & $216.42 \pm 119.31$ & $0.004617, \mathrm{~S}$ \\
\hline $\mathrm{k}_{\mathrm{el}}(1 / \mathrm{h})$ & $0.27 \pm 0.19$ & $0.33 \pm 0.19$ & $0.017293, \mathrm{~S}$ \\
\hline $\mathrm{t}_{1 / 2}(\mathrm{~h})$ & $3.55 \pm 1.94$ & $2.6 \pm 1.08$ & $0.017293, \mathrm{~S}$ \\
\hline $\mathrm{Cl} \mathrm{F}(\mathrm{L} / \mathrm{h})$ & $25.67 \pm 25.31$ & $31.24 \pm 19.36$ & $0.004617, \mathrm{~S}$ \\
\hline $\mathrm{Vz} \mathrm{F}(\mathrm{L})$ & $91.12 \pm 48.63$ & $100.51 \pm 53.9$ & $0.304896, \mathrm{NS}$
\end{tabular}

ANOVA $=$ Analysis of Variance $;{ }^{a}$ Data are presented as mean $\pm \mathrm{SD} ;{ }^{b}$ statistically significant when $\mathrm{p}<0.05 ; \mathrm{S}$ - statistically significant, NS - statistically non-significant

Table II

Pharmacokinetic (PK) parameters of zolpidem phenyl-4-carboxylic acid (Z4CA, zolpidem main metabolite) in 20 healthy volunteers, after a single oral dose of $5 \mathrm{mg}$ zolpidem, before and after pre-treatment with bupropion (BUP)

and the results of the statistical test used for comparison

\begin{tabular}{|c|c|c|c|}
\hline PK parameters $^{\mathrm{a}}$ & Z4CA & Z4CA + BUP & $p$ value $^{b}$, ANOVA \\
\hline $\mathrm{C}_{\max }(\mathrm{ng} / \mathrm{mL})$ & $117.08 \pm 37.55$ & $133.94 \pm 36.02$ & $0.020913, \mathrm{~S}$ \\
\hline $\mathrm{t}_{\max }(\mathrm{h})$ & $2.23 \pm 0.88$ & $2.38 \pm 0.96$ & $0.636290, \mathrm{NS}$ \\
\hline $\mathrm{AUC}_{0-\mathrm{t}}(\mathrm{ng} * \mathrm{~h} / \mathrm{mL})$ & $803.5 \pm 283.52$ & $838.23 \pm 272.5$ & $0.404780, \mathrm{NS}$ \\
\hline $\operatorname{AUC}_{0-\infty}(\mathrm{ng} * \mathrm{~h} / \mathrm{mL})$ & $827.46 \pm 287.78$ & $870.89 \pm 283.72$ & $0.338056, \mathrm{NS}$ \\
\hline $\mathrm{k}_{\mathrm{el}}(1 / \mathrm{h})$ & $0.18 \pm 0.12$ & $0.21 \pm 0.14$ & $0.356492, \mathrm{NS}$ \\
\hline$t_{1 / 2}(h)$ & $4.95 \pm 2.08$ & $4.59 \pm 2.37$ & $0.356492, \mathrm{NS}$ \\
\hline $\mathrm{Cl} / \mathrm{F}(\mathrm{L} / \mathrm{h})$ & $7.02 \pm 3.42$ & $6.61 \pm 3.49$ & $0.338056, \mathrm{NS}$ \\
\hline Vz_F (L) & $45.12 \pm 18.34$ & $37.22 \pm 13.92$ & $0.146389, \mathrm{NS}$ \\
\hline
\end{tabular}

ANOVA $=$ Analysis of Variance; ${ }^{a}$ Data are presented as mean $\pm \mathrm{SD} ;{ }^{\mathrm{b}}$ statistically significant when $\mathrm{p}<0.05$; $\mathrm{S}$ - statistically significant, NS - statistically non-significant

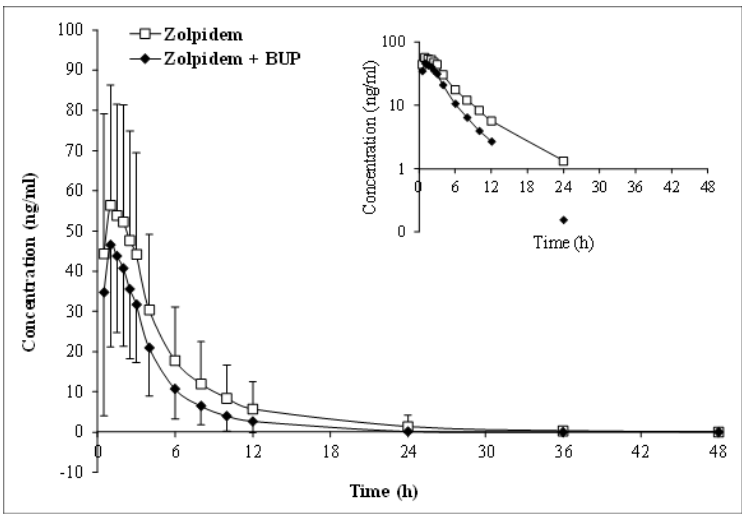

Figure 1.

Mean \pm SD plasma concentration - time curves of zolpidem (5 mg, p.o.) administered alone or in combination with bupropion (300 mg, p.o.) after pre-treatment with bupropion for 7 days, $\mathrm{n}=20$. Insert: semi-logarithmic presentation

The mean plasma concentration profiles over time for both analytes, before and after co-administration of bupropion, are depicted in Figure 1 (zolpidem) and Figure 2 (Z4CA).

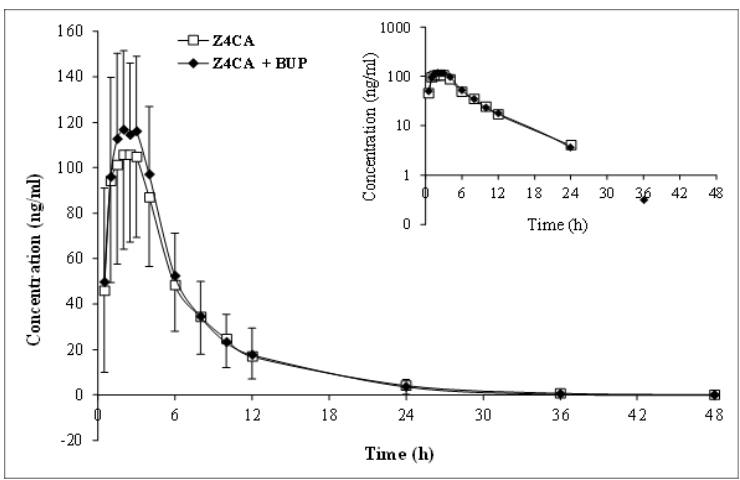

Figure 2.

Mean \pm SD plasma concentration-time curves of zolpidem phenyl-4-carboxylic acid (Z4CA, zolpidem main metabolite) corresponding to zolpidem ( $5 \mathrm{mg}$, p.o.) administered alone or in combination with bupropion (300 mg, p.o.), after pre-treatment with bupropion for 7 days, $n=20$. Insert: semi-logarithmic presentation 
The present investigation showed that exposure to zolpidem was decreased after bupropion pre-treatment, whereas an increased exposure to zolpidem's metabolite was also noticed which implied the existence of a metabolic drug-drug interaction between these drugs. More precisely, when the values corresponding to the Test study period (bupropion + zolpidem) were compared to the Reference study period (zolpidem alone), a reduction of about $20 \%$ was observed for the $\mathrm{C}_{\max }$ of zolpidem. The $\mathrm{AUC}_{0-\mathrm{t}}$ and $\mathrm{AUC}_{0-\infty}$ values for the parent drug also followed a downward trend of around $30 \%$ after bupropion multiple-dose pretreatment $\left(\mathrm{AUC}_{0-\mathrm{t}}: 327.06 \pm 241.11\right.$ vs $208.25 \pm 116.83$ $\mathrm{ng} * \mathrm{~h} / \mathrm{mL} ; \mathrm{AUC}_{0-\infty}: 340.34 \pm 249.02$ vs $216.42 \pm 119.31$ $\mathrm{ng} * \mathrm{~h} / \mathrm{mL}$ ). On the other hand, an increase of approximately $10 \%$ was reported for the $C_{\max }$ of Z4CA between study periods. The $\mathrm{AUC}_{0-\mathrm{t}}$ and $\mathrm{AUC}_{0-\infty}$ were also different for this metabolite between study periods as an increase of only $\sim 5 \%$ was noticed after bupropion intake. Other pharmacokinetic parameters like $t_{\max }, k_{\mathrm{el}}$ and $t_{1 / 2}$ displayed certain differences between treatment periods, for both parent compound and main metabolite, but in this case not all differences were statistically significant. The high values of standard deviations suggest a relatively high inter-individual variability, which was to be expected considering that the pharmacokinetics of zolpidem seems to be correlated with endocrine factors associated with CYP3A4 metabolism, probably influenced by the sex hormones $[6,23]$. The genetic variations to which CYP3A4 is subjected can be another contributing factor. Nonetheless, the latter explanation seems unlikely as the coding mutations in the CYP3A4 gene are rather rare and exhibit a limited effect on the intrinsic clearance of CYP3A substrates [19].

The main outcomes of the pharmacokinetic analysis suggest that a metabolism based drug-drug interaction between zolpidem and bupropion can be viewed as a possible explanation. More precisely, the results support the idea of an enzyme induction due to bupropion influence on the catalytic activity of CYP3A4, the main isoenzyme involved in zolpidem's biotransformation. As for the other isoenzymes involved in zolpidem's metabolism, one in vitro study performed on microsomes from baculovirus-infected insect cells concluded that bupropion demonstrated inhibitory effects on CYP2C19 and CYP2D6 activities while another study performed on rats showed that the antidepressant had no significant effect on CYP2C9mediated tolbutamide hydroxylation. Nonetheless, no enzyme-inducing properties were found for bupropion with regard to the activity of the aforementioned CYP450 isoenzymes $[17,26]$. The results obtained in the present research are very surprising since this is the first clinical trial to imply that bupropion can possibly alter the activity of CYP3A4. Counter to what is known in the literature about bupropion, this study revealed that this antidepressant may induce the catalytic activity of CYP3A4 and thus leading to lower plasma concentrations for zolpidem and higher plasma concentrations for zolpidem's metabolite when co-administered. The findings of this study are further relevant considering the fact that CYP3A4 is a CYP450 isoenzyme involved in the metabolism of many drugs and with a high susceptibility for metabolic drug-drug interactions [10].

The fact that this interaction occurs at both presystemic and systemic metabolism level is supported by the pharmacokinetic analysis along with the statistical evaluation. It is known that the CYP3A4 isoenzyme is expressed in both intestinal lumen and liver, accounting for approximately $80 \%$ of total $\mathrm{P} 450 \mathrm{~s}$ in the small intestine, quantity which represents $\sim 1 \%$ of the estimated hepatic levels [10]. The decrease registered for $\mathrm{C}_{\max }, \mathrm{AUC}_{0-\mathrm{t}}$ and $\mathrm{AUC}_{0-\infty}$ of zolpidem and increase of the same parameters for Z4CA are indicators of the interaction that occurred in the small intestine, in a pre-systemic manner, whilst the alteration of $\mathrm{Cl}$ F and consequently $\mathrm{k}_{\mathrm{el}}$ of both compounds suggests that the interaction also takes place in the liver, at systemic level. On the other hand, the modification of $\mathrm{Cl}$ - F can be accounted on the decreased bioavailability of zolpidem due to a pre-systemic interaction, considering that CYP3A4 is found in the small intestine, as it was previously mentioned.

Previous clinical trials which investigated the influence of bupropion on several different CYP450 isoformes didn't evaluate the possibility that bupropion can modify the catalytic activity of CYP3A4. The information is scarce, as only one study conducted on primary human hepatocytes addressed this issue. In this previous investigation, bupropion exhibited only a minimal alteration of CYP3A4 activity in comparison with rifampicin and the study concluded that multiple doses of this antidepressant are not likely to induce CYP3A4 in vivo, in human subjects [14]. Despite this, the present study is the first one to raise the hypothesis that bupropion can be a CYP3A4 inducer based on the current findings.

Another possibility that was considered with respect to the mechanism of induction was the modulation of P-glycoprotein activity. However, bupropion was proved to possess very weak affinity for P-glycoprotein while zolpidem is not only very unlikely to impair P-glycoprotein transport in vivo at the level of the gastro-intestinal tract, but is also not a drug whose transport is mediated by this energy-dependent efflux transporter [4, 37, 38].

A literature analysis that we performed in order to assess which other drugs are able to alter the pharmacokinetic profile of zolpidem concluded that the metabolism of this hypnotic agent can be influenced by co-administration with medications such as ciprofloxacin [34] or clarithromycin [20]. The mechanism involved in these drug-drug interactions is 
the enzymatic inhibition of CYP3A4. Our search also found an interaction between zolpidem and caffeine that is mediated by CYP1A2, in addition to other unknown mechanisms [7]. With respect to the effect of enzymatic inducers, the four main studies mentioned in the scientific literature evaluated the effects of rifampicin [33], carbamazepine [35], cigarette smoking [22] and St. John's Wort [15] on zolpidem clearance. It was concluded that the AUC ratio was 0.27 for rifampicin (most potent inducer), 0.43 for carbamazepine, 0.61 for smoking, and 0.67 for St. John's Wort [13]. The present study demonstrated that after association with bupropion, the AUC ratio is 0.67 , which suggests that, as an enzymatic inducer, bupropion has a similar potency to St. John's Wort, but is much weaker than potent inducers such as rifampicin and carbamazepine. Safety evaluation

During the study, the subjects experienced somnolence which was mainly attributed to zolpidem. This side effect was reported for 16 volunteers in both study periods. An analysis of the characteristics of this effect concluded that its mean duration was similar irrespective of bupropion concomitant intake (3.41 \pm 1.66 hours - reference vs $3.77 \pm 1.98$ hours - test). A small difference was observed for the onset of somnolence as during Study period 1, when only zolpidem was administered, the mean value recorded was $58.63 \pm 38.86$ minutes, whilst during Study period 2, when zolpidem was co-administered with bupropion, the reported mean value was of $51.88 \pm$ 27.78 minutes. With regards to the intensity, 11 subjects showed an increased sleepiness after bupropion concomitant intake, 5 showed no differences in intensity and for 4 subjects it was reported that the side-effect diminished during Study period 2. Therefore, considering the safety analysis results, the preliminary data does not suggest a potential clinical relevance for this PK interaction. However, these results can be viewed insufficient in order to draw a final conclusion, especially considering that in this study zolpidem was administered only as single-dose and in such instances, the information cannot always be extrapolated to multiple-dose regimens.

\section{Conclusions}

In this clinical trial, the multiple dose treatment regimen of bupropion had an impact on the metabolism of co-administered zolpidem, leading to lower plasma drug concentrations for the parent compound and higher ones for the main metabolite, Z4CA. Overall, zolpidem and bupropion combination resulted in an approximately $30 \%$ decreased exposure for zolpidem. Zolpidem metabolite (Z4CA) pharmacokinetics was also modified, but to a lesser extent. The present study is the first clinical trial to suggest that bupropion may have enzymatic induction properties over CYP3A4. Nonetheless, further investigations are required in order to elucidate the mechanism of this PK drug interaction and to assess its potential clinical consequences.

\section{Acknowledgement}

This work was supported by the National Research Council (CNCS) Romania - project PN-II-ID-PCE2011-3-0731. All authors are full-time employees of the "Iuliu Haţieganu" University of Medicine and Pharmacy, Cluj-Napoca, Romania.

\section{Conflict of interest}

There are no conflicts of interest to be declared.

\section{References}

1. Abrudan MB, Muntean DM, Gheldiu AM, Neag MA, Vlase L, The Pharmacokinetic Interaction Study between Carvedilol and Bupropion in Rats. Pharmacology, 2017; 99(3-4): 139-143.

2. Alberti S, Chiesa A, Andrisano C, Serretti A, Insomnia and somnolence associated with secondgeneration antidepressants during the treatment of major depression: a meta-analysis. J Clin Psychopharmacol., 2015; 35(3): 296-303.

3. Atkin T, Comai S, Gobbi G, Drugs for insomnia beyond benzodiazepines: pharmacology, clinical applications, and discovery. Pharmacol Rev., 2018; 70(2): 197-245.

4. Becker S, Liu X, Evaluation of the utility of brain slice methods to study brain penetration. Drug Metab Dispos., 2006; 34(5): 855-861.

5. Briciu C, Neag M, Muntean D, Vlase L, Bocşan C, Buzoianu A, Gheldiu AM, Achim M, Popa A, A pharmacokinetic drug interaction between nebivolol and paroxetine in healthy volunteers. J Clin Pharm Ther., 2014; 39(5): 535-540.

6. Cubała WJ, Wiglusz M, Burkiewicz A, Zolpidem pharmacokinetics and pharmacodynamics in metabolic interactions involving CYP3A: sex as a differentiating factor. Eur J Clin Pharmacol., 2010; 66(9): 955.

7. Cysneiros RM, Farkas D, Harmatz JS, von Moltke LL, Greenblatt DJ, Pharmacokinetic and pharmacodynamic interactions between zolpidem and caffeine. Clin Pharmacol \& Ther., 2007; 82(1): 54-62.

8. Dang A, Garg A, Rataboli PV, Role of zolpidem in the management of insomnia. CNS Neurosci Ther., 2011; 17: 387-397.

9. Faul F, Erdfelder E, Lang AG, Buchner A, G*Power 3: A flexible statistical power analysis program for the social, behavioral, and biomedical sciences. Behav Res Meth., 2007; 39(2): 175-191.

10. Galetin A, Gertz M, Houston JB, Contribution of intestinal cytochrome P450-mediated metabolism to drug-drug inhibition and induction interactions. Drug Metab Pharmacokinet., 2010; 25(1): 28-47.

11. Gheldiu AM, Popa A, Neag M, Muntean D, Bocşan C, Buzoianu A, Vlase L, Tomuţă I, Briciu C, Assessment of a potential interaction between nebivolol and bupropion in healthy volunteers. Pharmacology, 2016; 98(3-4): 190-198. 
12. Gheldiu AM, Popa A, Neag M, Muntean D, Bocşan C, Buzoianu A, Vlase L, Marcela Achim, Todor I, Briciu C, Assessment of fluvoxamine effects on the pharmacokinetics of zolpidem and its metabolite in healthy volunteers. Farmacia, 2015; 63(3): 453-459.

13. Greenblatt DJ, Roth T, Zolpidem for insomnia. Expert Opin Pharmacother., 2012; 13(6): 879-893.

14. Hesse LM, Sakai Y, Vishnuvardhan D, Li AP, von Moltke LL, Greenblatt DJ, Effect of bupropion on CYP2B6 and CYP3A4 catalytic activity, immunoreactive protein and mRNA levels in primary human hepatocytes: comparison with rifampicin. $J$ Pharm Pharmacol., 2003; 55(9): 1229-1239.

15. Hojo Y, Echizenya M, Ohkubo T, Drug interaction between St John's wort and zolpidem in healthy subjects. J Clin Pharm Ther., 2011; 36(6): 711-715.

16. Jefferson JW, Pradko JF, Muir KT, Bupropion for major depressive disorder: pharmacokinetic and formulation considerations. Clin Ther., 2005; 27(11): 1685-1695.

17. Kim HK, Chai S, Oh HG, Lee SS, Sohn DR, Yom YK, Kwon JT, Effects of bupropion on oxidation metabolism catalyzed by human cytochrome P450 isoenzymes (CYP3A4, CYP2A6, CYP2C19 and CYP2D6). J Kor Soc Clin Pharmacol Ther., 2010; 18(2): 111-119.

18. Krylova EA, Kataev SS, Khomov YA, Determination of zolpidem and its metabolites by chromatographymass spectrometry. J Anal Chem., 2013; 68(8): 722-729.

19. Lamba JK, Lin YS, Schuetz EG, Thummel KE, Genetic contribution to variable human CYP3A-mediated metabolism. Adv Drug Deliv Rev., 2002; 54(10): 1271-1294.

20. Lee YJ, Byeon JY, Kim SH, Kim YH, Lee HJ, Lee Y, Kim DH, Lim HJ, Jang CG, Lee SY, Significant drugdrug interaction between zolpidem and clarithromycin [abstract]. Clin Ther., 2015; 37(8): e-138. www.clinical therapeutics.com/article/S0149-2918(15)00703-1.

21. Monti JM, Spence DW, Buttoo K, Zolpidem's use for insomnia. As J Psychiatr., 2017; 25: 79-90.

22. Olubodun JO, Ochs HR, Trüten V, Klein A, von Moltke LL, Harmatz JS, Shader RI, Greenblatt DJ, Zolpidem pharmacokinetic properties in young females: influence of smoking and oral contraceptive use. $J$ Clin Pharmacol., 2002; 42(10): 1142-1146.

23. Olubodun JO, Ochs HR, von Moltke LL, Hesse LM, Harmatz JS, Shader RI, Greenblatt DJ, Pharmacokinetic properties of zolpidem in elderly and young adults: possible modulation by testosterone in men. J Clin Pharmacol., 2003; 56(3): 297-230.

24. Patel DK, Stanford FC, Safety and tolerability of new-generation anti-obesity medications: a narrative review. Postgrad Med., 2018; 130(2): 173-182.

25. Patterson F, Grandner MA, Malone SK, Rizzo A, Davey A, Edwards DG, Sleep as a target for optimized response to smoking cessation treatment. Nicotine Tob Res., 2019; 21(2): 139-148.

26. Qiu X, Song J, Yuan H, Hou Y, Pan X, Xu R-A, Evaluation of CYP2C9 Activity in Rats: Use of tolbutamide alone and in combined with bupropion. Ir J Pharm Res., 2014; 13(2): 635-639.

27. Saiz Ruiz J, Gibert J, Gutiérrez Fraile M, Bobes J, Vallejo J, Iglesias C, Iriarte V, Bupropion: efficacy and safety in the treatment of depression. Actas Esp Psiquiatr., 2011; 39(Suppl 1): 1-25.

28. Schroeck JL, Ford J, Conway EL, Kurtzhalts KE, Gee ME, Vollmer KA, Mergenhagen KA, Review of safety and efficacy of sleep medicines in older adults. Clin Ther., 2016; 38(11): 2340-2372.

29. Sivertsen B, Salo P, Mykletun A, Hysing M, Pallesen S, Krokstad S, Nordhus IH, Øverland S, The bidirectional association between depression and insomnia: the HUNT study. Psychosom Med., 2012; 74(7): 758-765.

30. Staner L, Comorbidity of insomnia and depression. Sleep Med Rev., 2010; 14(1): 35-46.

31. Todor I, Popa A, Neag M, Muntean D, Bocşan C, Buzoianu A, Vlase L, Gheldiu AM, Briciu C, Evaluation of a Potential Metabolism-Mediated Drug-Drug Interaction Between Atomoxetine and Bupropion in Healthy Volunteers. J Pharm Pharm Sci., 2016; 19(2): 198-207.

32. Verbeeck W, Bekkering GE, Van den Noortgate W, Kramers C, Bupropion for attention deficit hyperactivity disorder (ADHD) in adults. Cochrane Database Syst Rev., 2017; 10: CD009504. www.cochrane library.com/cdsr/doi/10.1002/14651858.CD009504 .pub2/epdf/full.

33. Villikka K, Kivistö KT, Luurila H, Neuvonen PJ, Rifampin reduces plasma concentrations and effects of zolpidem. Clin Pharmacol Ther., 1997; 62(6): 629-634.

34. Vlase L, Popa A, Neag M, Muntean D, Leucuţa SE, Pharmacokinetic interaction between zolpidem and ciprofloxacin in healthy volunteers. Eur $J$ Drug Metab Pharmacokinet., 2011; 35(3-4): 83-87.

35. Vlase L, Popa A, Neag M, Muntean D, Bâldea I, Leucuţa SE, Pharmacokinetic interaction between zolpidem and carbamazepine in healthy volunteers. J Clin Pharmacol., 2011; 51(8): 1233-1236.

36. Von Moltke LL, Greenblatt DJ, Granda BW, Duan SX, Venkatakrishnan K, Harmatz JS, Zolpidem metabolism in vitro: responsible cytochromes, chemical inhibitors, and in vivo correlations. Br J Clin Pharmacol., 1999; 48(1): 89-97.

37. Von Moltke LL, Weemhoff JL., Perloff MD, Hesse LM, Harmatz JS, Roth-Schechter BF, Greenblatt DJ, Effect of zolpidem on human cytochrome P450 activity and on transport mediated P-glycoprotein. Biopharm Drug Dispos., 2002; 23(9): 361-367.

38. Wang JS., Zhu HJ., Gibson BB, Markowitz JS, Donovan JL, DeVane CL, Sertraline and its metabolite desmethylsertraline, but not bupropion or its three major metabolites, have high affinity for P-glycoprotein. Biol Pharm Bull., 2008; 31(2): 231-234.

39. Wichniak A, Wierzbicka A, Jernajczyk W, Sleep and antidepressant treatment. Curr Pharm Des., 2012; 18(36): 5802-5817.

40. Zhang Y, Zhang L, Shi H, Sun J, Gao S, Keqing L, Efficacy of paroxetine and mirtazapine on sleep in patients with depression and their relationship with polysomnography. Farmacia, 2018; 66(1): 157-164.

41. Wilkes S, The use of bupropion SR in cigarette smoking cessation. Int $J$ Chron Obstruct Pulmon Dis., 2008; 3(1): 45-53. 